\title{
A avaliação psicológica da atividade voluntária a partir da Psicologia Histórico-Cultural: os instrumentos desenvolvidos no México
}

\author{
Ana Paula Alves Vieira', https://orcid.org/0000-0002-4771-3476 \\ Záira Fátima de Rezende Gonzalez Leal' ${ }^{1}$, https://orcid.org/0000-0001-5692-4243 \\ Yulia Solovieva ${ }^{2}$, https://orcid.org/0000-0001-5610-1474
}

\section{Resumo}

Uma das queixas que chegam ao psicólogo escolar/educacional é referente à falta de controle de comportamento expressa pela criança. Diante disso, cobra-se do profissional a realização de avaliação psicológica para diagnóstico das dificuldades, porém muitas dessas avaliações realizam um diagnóstico de forma que rotula a criança sem, contudo, contribuir para seu desenvolvimento. Considerando que o aparato teóricometodológico da psicologia histórico-cultural permite a compreensão do desenvolvimento humano como de ordem social, buscamos discutir como o psicólogo poderia avaliar as crianças de uma forma condizente com essa teoria. Dessa forma, este artigo, que é parte de uma dissertação de mestrado, apresenta um instrumento de avaliação psicológica no que se refere à atividade voluntária, desenvolvido pela Maestría en Diagnóstico y Rehabilitación Neuropsicológica (Benemérita Universidad Autónoma de Puebla - Puebla, México) à luz da neuropsicologia e psicologia histórico-cultural. Espera-se instrumentalizar psicólogos escolares/educacionais a enfrentar os crescentes diagnósticos estigmatizantes, bem como auxiliar futuras pesquisas.

Palavras-chave: Avaliação psicológica; Psicologia Histórico-Cultural; desenvolvimento infantil.

\section{The psychological evaluation of voluntary activity from Historical-Cultural}

\author{
Psychology: the instruments developed in Mexico
}

\begin{abstract}
One of the complaints that comes to the school and educational psychologist is about children with issues on controlling their own behavior. For this reason, the professional is charged with performing a psychological assessment to diagnose difficulties, but many of these evaluations carry out a diagnostic in a way that labels the child without, therefore, contributing to its development. Considering that the theoretical-methodological apparatus of historical-cultural psychology allows the understanding of human development as a social order, we discuss how to evaluate children based on this theory. Thus, this article, which is part of a Master thesis, it presents a voluntary activity evaluation instrument developed by the Maestría en Diagnóstico y Rehabilitación Neuropsicológica (Benemérita Universidad Autónoma de Puebla - Puebla, México) from the neuropsychology and historical-cultural psychology. It is expected that the research will contribute to instrumentalize school and educational psychologists to face the increasing diagnostic labels and to support future researches.
\end{abstract}

Keywords: Psychological evaluation; Historical-Cultural Psychology; childhood development.

\section{La evaluación psicológica de la actividad voluntaria desde la Psicología Histórico-Cultural: los protocolos desarrollados en México}

\begin{abstract}
Resumen para hacer frente al aumento de los diagnósticos estigmatizados, así como ayudar a futuras investigaciones.

Palabras clave: Evaluación psicológica; Psicología Histórico-Cultural; desarrollo infantil.

1 Universidade Estadual de Maringá, Maringá - PR, Brasil; avieira.ap@gmail.com; zairagleal@gmail.com

2 Benemérita Universidad Autónoma de Puebla, Puebla, México; yulia.solovieva@correo.buap.mx
\end{abstract}

Uno de los problemas, a los que se enfrenta psicólogo escolar/educativo, se refiere a la falta de control del comportamiento expresada en el niño. Así pues, el profesional debe realizar una evaluación psicológica para diagnosticar las dificultades, sin embargo, muchas de esas evaluaciones son realizadas de forma que rotula el niño y no contribuye para su desarrollo. La Psicología Histórico-Cultural permite la comprensión del desarrollo humano de forma social, por eso buscamos discutir como el psicólogo puede realizar evaluaciones desde esa teoría. El presente artículo representa una parte de la tesina de Maestría y tiene como objetivo presentar el protocolo de evaluación psicológica de la actividad voluntaria desarrollado desde la Neuropsicología y Psicología Histórico-Cultural por la Maestría en Diagnóstico y Rehabilitación Neuropsicológica (Benemérita Universidad Autónoma de Puebla - Puebla, México). Se espera compartir las herramientas con psicólogos escolares/educativos, 


\section{Introdução}

Uma das grandes queixas que chegam ao psicólogo escolar/educacional é referente à falta de controle de comportamento expressa pela criança e, diante disso, o profissional, em geral, realiza uma avaliação psicológica para averiguar os problemas que a criança apresenta. Entretanto muitas dessas avaliações são realizadas de forma que rotula a criança e não contribui para a compreensão acerca de seu comportamento e para seu desenvolvimento. Considerando que o aparato teórico-metodológico da psicologia histórico-cultural permite a compreensão do desenvolvimento humano como de ordem social, realizar uma avaliação segundo essa abordagem, com instrumentos adequados à compreensão e verificação da queixa, pode ser uma importante contribuição ao psicólogo educacional/escolar, convertendo a avaliação em ferramenta interessante para o desempenho profissional.

Nesse sentido, com o intuito de contribuir para a reflexão sobre o diagnóstico e a avaliação a partir da psicologia e neuropsicologia histórico-cultural, apresentaremos o instrumento que se refere à avaliação da atividade voluntária desenvolvido pela Maestría en Diagnóstico y Rehabilitación Neuropsicológica, pertencente à Benemérita Universidad Autónoma de Puebla, na cidade de Puebla, no México, baseado nesse enfoque. Este artigo, portanto, é derivado da pesquisa de mestrado vinculada à linha de pesquisa Desenvolvimento Humano e Processos Educativos do programa de Pós-graduação em Psicologia da Universidade Estadual de Maringá (UEM, 2015-2017), que contemplou um período 'sanduíche' na instituição mencionada.

\section{Pressupostos básicos da Psicologia Histórico- Cultural}

Os principais fundadores da psicologia e neuropsicologia histórico-cultural foram os autores soviéticos L. S. Vigotski1 (1896-1934), A. R. Luria (1902-1977) e A. N. Leontiev (1903-1979). Para este enfoque teórico, psicologia é a ciência das funções cerebrais e dos fenômenos psíquicos que refletem uma realidade objetiva, constituída pela história e compreendida em seu dinamismo. Dessa forma, Sokolov e Rubinstein (1969) afirmam que se compreendemos o mecanismo fisiológico pelo qual se passa o reflexo da realidade no cérebro, compreendemos que a diferença entre material e ideal (como postulam outros enfoques) é relativa e não absoluta. O cérebro transforma a excitação externa em sensações, percepções, sentimentos e pensamentos, portanto a consciência e a atividade cerebral não se separam, dessa forma, não existem ideias "puras" ou "não materiais", como postulam os idealistas, nem existem somente "secreções cerebrais", como afirmam os materialistas vulgares.

1 Optamos por utilizar a grafia Vigotski no corpo deste trabalho, porém nas citações e nas referências será mantida a grafia de acordo com a obra consultada.
Sobre a atividade consciente do homem, os investigadores que fundamentam seus estudos nos princípios do materialismo histórico possuem uma posição completamente diferente dos materialistas citados anteriormente, bem como dos idealistas. Para os autores histórico-culturais, o processo histórico do desenvolvimento do homem se relaciona com o surgimento do trabalho e com o surgimento da linguagem (Marx, 1867/2013; Luria, 1991).

A concepção de Vigotski propõe-se a identificar os componentes essenciais do processo de desenvolvimento psicológico, o qual é compreendido como o desenvolvimento histórico-cultural, diferente de outras concepções que entendem o desenvolvimento como biológico ou evolutivo. Para que o desenvolvimento psicológico aconteça, se requerem condições orgânicas e sociais correspondentes. As condições orgânicas consistem no estado ótimo do sistema nervoso da criança quando nasce, enquanto as condições sociais incluem as situações sociais adequadas para seu desenvolvimento (Vigotsky, 1996). Vale ressaltar que a origem do desenvolvimento psicológico corresponde à cultura humana, sendo que esse processo se dá a partir da aquisição da experiência histórico-cultural. Nesse sentido, os psicólogos do desenvolvimento compreendem o desenvolvimento ontogenético como as diversas formas de aquisição da experiência cultural acessível e necessária para cada período do desenvolvimento. Considera-se que a experiência cultural não pode ser adquirida de forma espontânea, mas sim a partir da interação ativa da criança: a partir da atividade principal correspondente ao seu período de desenvolvimento.

Nesse sentido, sobre a periodização do desenvolvimento proposta por essa escola psicológica, é importante entender o desenvolvimento humano como um processo dialético ${ }_{\perp}$ contraditório e revolucionário, que não ocorre de forma evolutiva progressiva, mas por interrupções da continuidade - crises, saltos - e pelo surgimento de novas formações (Vigotsky, 1996; Elkonin, 1987). De acordo com Elkonin (1987), a introdução do conceito de atividade proposto por Leontiev e Rubinstein foi importante na formulação dos princípios de divisão dos estágios do desenvolvimento. Sobre a definição de atividade, Leontiev (1972), afirma:

\footnotetext{
... é em atividade que a transição ou "tradução" do objeto refletido em imagem subjetiva, em ideal, ocorre; ao mesmo tempo, é também em atividade que a transição é alcançada do ideal em resultados objetivos da atividade, seus produtos, em material. Considerada deste ângulo, atividade é um processo de inter-tráfico entre polos opostos, sujeito e objeto (para. 10).
}

De acordo com os representantes da teoria da atividade, a relação entre a criança e o meio cultural se introduz desde o início. O primeiro contato cultural ao qual se dirige a atividade comunicativa da criança é o adulto cuidador portador dessa atividade, que em sua estrutura inclui signo e significado (Leontiev, 1984). Segundo Leontiev (citado por Elkonin, 1987), o estudo do desenvolvimento do psiquismo 
deve partir do desenvolvimento da atividade da criança, de como ela se forma nas condições concretas da vida. $\mathrm{O}$ autor introduz o conceito de atividade principal que caracteriza os períodos do desenvolvimento psíquico. A passagem de um estágio ao outro corresponde à mudança na atividade principal, ou seja, do tipo de relação da criança com a realidade.

Elkonin (1987) afirma que a vida da criança é composta por diferentes atividades e em cada período algumas surgem e se convertem em atividades principais, dessa forma não se elimina as existentes anteriores, apenas ocorre uma mudança de seu lugar no sistema geral de relações da criança com a realidade. O autor caracterizou os períodos do desenvolvimento de acordo com as atividades guias da seguinte forma: 1. Comunicação emocional direta; 2 . Atividade objetal manipulatória; 3. Jogo de papéis; 4. Atividade de estudo; 5. Comunicação íntima pessoal; 6. Atividade profissional de estudo.

De acordo com Vigotski (citado por Elkonin, 1987) o estudo do desenvolvimento infantil consiste em estudar a passagem da criança de um degrau a outro e a mudança em sua personalidade em cada período, tendo em conta as condições histórico-sociais concretas.

\section{Conceituando a atividade voluntária}

O termo "atividade voluntária" ou "voluntariedade" é próprio da escola histórico-cultural (Solovieva \& Quintanar, 2001; Salmina \& Filimonova, 2001). De acordo com Solovieva e Quintanar (2001), o caráter voluntário não está relacionado com uma função, mas com a formação adequada de todos os processos psicológicos superiores e se relaciona com a organização da atenção, da memória, da linguagem, do pensamento e da esfera afetivo-emocional.

Vigotski não usava propriamente o termo atividade, postulando acerca da voluntariedade, do autocontrole, do autodomínio e da autorregulação, mas não aponta uma distinção entre esses processos (Vieira, 2016). Vygotsky (1931/2012, p. 84) questiona "O que devemos entender como domínio da própria conduta?". O autor responde que assim como o domínio da natureza não pressupõe a abolição das leis básicas da natureza, o domínio do próprio comportamento também não, mas sim uma subordinação dessas leis. A lei básica da conduta, de acordo com Vygotsky (1931/2012), consiste na lei de estímulo-resposta; dessa forma, a dominação do comportamento corresponde a uma dominação dos estímulos. O ser humano significa o estímulo, ou seja, atribui significado histórico para o estímulo.

Vygotsky (1931/2012) cita exemplos sobre a autodominação por meio dos estímulos: em uma situação na qual uma pessoa precisa esperar muito tempo em uma habitação vazia e não sabe se continua esperando ou se vai embora (conflito de motivos), o comportamento de olhar o relógio intensifica um dos motivos, por exemplo, se for tarde ela decidirá ir embora. O relógio se converte em estímulo e adquire o significado de um motivo auxiliar; dessa forma, o sujeito pode delimitar um horário para se levantar e sair.
O autor afirma, no texto El problema de la edad cultural (Vygotsky, 1931/2012), que o que muda durante o processo de desenvolvimento do comportamento não são as funções, mas as relações entre as funções, pois surgem novos agrupamentos. Essas novas relações entre as funções são denominadas sistemas psicológicos, conceito que foi melhor desenvolvido por Leontiev e Luria depois da morte de Vigotski.

Para Leontiev (1984), a formação dos sistemas funcionais específicos do homem também é resultado do domínio dos instrumentos e operações. Para o autor, a expressão concreta das funções psicofisiológicas se modifica dependendo do conteúdo da atividade do sujeito e a tarefa científica não é constatar essa dependência, como fazem numerosos psicólogos e fisiólogos, mas “... investigar as transformações da atividade que conduzem a reestruturar o conjunto das funções psicofisiológicas cerebrais" (p. 92).

Sobre a atividade voluntária, Leontiev relaciona seu desenvolvimento com o desenvolvimento da esfera motivacional. $\mathrm{O}$ autor postula que a característica principal da atividade voluntária é o fato de que "a execução da ação é possível apenas mediante a presença da relação do motivo e do objetivo" (Smirnova, 2010, p. 49). A pesquisadora $\mathrm{Ne}$ pomniaschaya (1965 citado por Smirnova, 2010) afirma, a partir de experimentos, que a presença dessa relação acontece pela primeira vez na metade da infância pré-escolar, ou seja, é nessa idade que ações voluntárias são possíveis. Para Leontiev (2010), aos três anos de idade a criança começa a dirigir sua atividade pela subordinação dos motivos em ações isoladas e não mais por motivos isolados. A criança aspira à conquista de um objetivo que pode não ser atrativo, assim como rejeita uma coisa imediata que é atrativa visando conquistar algo mais importante ou escapar de algo que não é agradável. Nesse sentido, duas ações isoladas têm um sentido mais complexo, pois dependem do motivo que as submete. Esse ato de identificar os motivos mais relevantes que submetem aos outros - correlação dos motivos - é encontrado pela primeira vez na idade pré-escolar (Leontiev, 2010).

Outro fator fundamental nesse processo consiste em que a subordinação dos motivos se forma primeiramente na comunicação com o adulto, a partir de suas exigências (Leontiev, 2010). Sobre o papel da linguagem no desenvolvimento da ação voluntária da criança, Luria (1962/2015) afirma que primeiro a ação da criança se determina pela ordem do adulto (ação repartida entre pessoas), depois se converte em uma ação regulada pela própria criança, primeiro por sua atividade perceptiva, depois pela sua linguagem externa desenvolvida e, posteriormente, por ideias e esquemas formulados pela participação da linguagem interna. Essa linguagem desenvolvida por último participa na transformação da informação recebida em ação com objetivo.

Luria (1962/2015) afirma que o componente verbal é a base das formas mais complexas de regulação do ato motor voluntário complexo (em ações voluntárias mais simples o componente verbal é menos necessário, já que essas ações se limitam na formulação do propósito e na realização 
de estereótipos motores). Portanto, a ação complexa que exige separar o sistema essencial de relações, criar um sistema interno de ação que seja dominante, abandonando as reações colaterais e inadequadas, depende do componente verbal. Apesar da criação de um esquema geral de ação, a influência reguladora da linguagem externa ou interna está também no transcurso da realização da ação, ou seja, no processo de vigilância e de controle da efetividade da ação. Dessa forma, a linguagem “... ajuda a comparar a ação realizada com o propósito inicial, formulando sinais de concordância ou discordância, corrigindo os erros cometidos, interrompendo a atividade se o objetivo foi cumprido, ou reformulando-a se tal objetivo não foi conquistado" (Luria, 1962/2015, p. 299).

Quintanar e Solovieva (2013) afirmam que a atividade voluntária é a atividade dirigida a um objetivo estabelecido. Em diferentes idades é possível identificar objetos e objetivos diferentes nas atividades. Nos primeiros anos de vida, a atividade voluntária é compartilhada entre a criança e o adulto nas situações comunicativas afetivas. $O$ adulto introduz os objetivos comunicativos, enquanto a criança os retoma e atua com gestos, expressões faciais, movimentos corporais e com as primeiras vocalizações. Já na idade pré-escolar a atividade voluntária se desenvolve no jogo de papéis. Dessa forma, gradualmente a criança propõe seus próprios objetivos e desenvolve a atividade voluntária. $\mathrm{Na}$ etapa escolar a criança já pode organizar, controlar e verificar sua atividade de forma voluntária, ou seja, já tem o controle interno.

Leontiev (1972/2009) afirma que por trás da atividade está o trabalho cerebral-fisiológico e que "portanto, o cérebro não permanece psicologicamente calado" (p. 63). Dessa forma introduz, junto com Luria e outros teóricos do enfoque histórico-cultural, o conceito de "blocos funcionais" para aprofundar a análise em unidades mais fracionadas, buscando os vínculos que formam a estrutura dos processos que realizam fisiologicamente a atividade.

Nesse sentido, Luria desenvolve a tese de Vigotski acerca das ações voluntárias e busca seu desenvolvimento no cérebro. Baseado nas premissas da Psicologia Histórico-cultural, o autor compreende as funções psicológicas de forma sistêmica e dinâmica. Sistêmica significa que as funções estão organizadas em sistemas funcionais complexos, integradas por distintas áreas do cérebro, em que cada uma tem responsabilidade sobre a função. Dinâmica significa que os sistemas não são estáticos, ou seja, modificam com a idade e com a aprendizagem (Luria, 1962/2015).

Na concepção neuropsicológica de A. R Luria, o sistema funcional complexo representa não uma função psicológica, mas sim toda a atividade ou ação. O sistema funcional complexo inclui a participação de diferentes componentes do trabalho cerebral e nunca pode ser levada a cabo por um único mecanismo cerebral (ou fator, como denomina Luria). Pode surgir a impressão de que a atividade voluntária se realiza com a participação dos lóbulos frontais e seus mecanismos (regulação e controle), porém consideramos importante sinalizar que esta impressão não está correta. A atividade voluntária deve ser compreendida como um tipo de atividade e não como um mecanismo cerebral. A atividade voluntária não pode se compreender como sinônimo de regulação e controle, portanto deve-se analisá-la pelo seu conteúdo concreto (por exemplo: jogo voluntário, leitura voluntária, escrita voluntária) e não como um constructo abstrato que se refere apenas aos lóbulos frontais. Para a análise neuropsicológica precisa, o especialista deve realizar a análise do conteúdo da atividade para precisar o sistema funcional que o subjaz. Para a análise psicológica, no caso da avaliação do nível do desenvolvimento, transcurso da idade ou preparação da criança para a escola, o psicólogo caracteriza a atividade voluntária como neoformação psicológica da idade, não podendo reduzi-la a nenhum mecanismo ou estrutura cerebral.

\section{A avaliação da atividade voluntária: método}

As queixas de crianças com dificuldade em controlar o comportamento na escola são frequentes ao psicólogo e esse profissional é cobrado para realizar uma avaliação da criança. Muitos psicólogos brasileiros utilizam materiais psicométricos, como aponta uma pesquisa de Facci, Tessaro, Leal, Silva e Roma (2007). Também atuam embasados pelo Manual Diagnóstico e Estatístico de Transtornos Mentais (DSM), instituído pela Associação Estadunidense de Psicologia. Lázaro Garcia (2009) aponta que o manual DSM está relacionado à análise tradicional das dificuldades de aprendizagem que determina um tratamento sintomático, ou seja, a análise é feita considerando-se funções como processos isolados (memória, atenção, pensamento etc.), sendo que a soma dessas funções corresponde ao processo de aprendizagem (processo passivo). São exemplos disso os diagnósticos de dislexia, disgrafia e discalculia para referir-se a transtornos de leitura, escrita e cálculo, respectivamente.

As avaliações tradicionais realizadas cumprem, desde o século XIX, uma função de medir a inteligência e de classificar as crianças como capazes ou não capazes de aprender, colocando a culpa do problema do processo de escolarização unicamente no estudante (Patto, 1990). Dessa forma, geralmente as crianças são avaliadas pelos psicólogos e obtêm diagnósticos que Ihes responsabilizam pelas suas dificuldades na escola, recebem rótulos de agressivos, hiperativos ou incapazes de aprender, encobrindo as dimensões sociais e políticas que produzem essas queixas (Asbahr \& Lopes, 2006).

Facci e cols. (2007) afirmam que, tomando por base uma abordagem psicométrica, é possível remeter-se à concepção inatista do desenvolvimento, caracterizada por compreender a constituição do ser humano a partir de fatores maturacionais e hereditários. Leontiev (1959/1991) também questiona o valor das investigações de médicos e psicólogos sobre o atraso mental: "A que resultado final conduzem os seus diagnósticos e prognósticos, os seus métodos de seleção? Podem conduzir à diminuição do número de crianças classificadas como mentalmente subdesenvolvidas, ou determinam talvez o resultado oposto?" (p. 109). Dessa forma, 
os autores histórico-culturais não negam o valor das avaliações psicológicas, mas questionam o seu limite quando se avalia somente o desenvolvimento já consolidado e não o desenvolvimento emergente, sendo assim, o que importa são as possibilidades de superação social da criança e não sua rotulação ou classificação (Mello, 2013).

Dessa forma, atualmente cresce o interesse pela abordagem histórico-cultural na educação regular e especial, principalmente no que se refere à solução e prevenção das dificuldades escolares (Solovieva, Lázaro, \& Quintanar, 2006). Na Rússia, têm-se desenvolvido procedimentos de avaliações e métodos de correção ${ }^{2}$ para crianças pré-escolares e escolares, principalmente por Akhutina, Pilayeva e outros pesquisadores que estudam a neuropsicologia infantil (Quintanar \& Solovieva, 2008; Xomskaya, 2002).

Esses estudos desenvolvidos na Rússia constituíram um "guia metodológico para a elaboração de estratégias corretivas na Maestría en Diagnóstico y Rehabilitación Neuropsicológica no México" (Quintanar \& Solovieva, 2008, p. 151). Assim, muitos procedimentos de avaliação e métodos de correção foram desenvolvidos a partir dos pressupostos da escola histórico-cultural por essa instituição de reconhecimento internacional. Esses instrumentos permitem uma análise qualitativa em nível psicológico e neuropsicológico e diferenciam-se das outras avaliações porque não têm como objetivo simplesmente a identificação de sintomas e o tratamento direto destes (Quintanar \& Solovieva, 2008)

Compreendemos que a atividade voluntária, como toda atividade, envolve diferentes mecanismos cerebrais, se refere a uma categoria psicológica e, portanto, deve ser analisada como tal. Para se realizar uma análise psicológica desse processo em questão, esse é considerado uma neoformação do período pré-escolar, como explicitamos anteriormente, e se deve identificar até onde a criança precisa da ajuda do adulto, o tipo de ajuda que necessita, como se regula a partir da linguagem, os instrumentos e estratégias que usa para realizar a tarefa (Quintanar \& Solovieva, 2003).

Uma avaliação da atividade voluntária baseada nas leis de comportamento propostas pelos teóricos da psicologia histórico-cultural, de acordo com Luria (1994 citado por Facci, Eidt \& Tuleski, 2006), auxilia avaliações e práticas pedagógicas que se preocupam não com as qualidades naturais da criança, mas com a utilização de mediadores culturais. Essas avaliações possibilitam entender de uma forma mais pontual as dificuldades e as potencialidades das crianças. Na avaliação podem-se observar os processos psicológicos que estão ocorrendo e se desenvolvendo e que os psicólogos e investigadores devem não apenas observar, mas também formar as atividades correspondentes para a educação e o desenvolvimento da criança (Solovieva, 2014). Essa análise é possibilitada pelos estudos de Vigotski

2 Correção é um termo utilizado para se referir aos procedimentos de tratamentos, assim como reabilitação, estimulação, remediação, apoio psicopedagógico ou intervenção acadêmica. Os autores propõem o uso do termo de correção neuropsicológica para crianças com dificuldades, em consonância com uma nova proposta de neuropsicólogos da escola histórico-cultural (Solovieva \& Quintanar, 2014).
(1934/2009) referentes à zona de desenvolvimento próximo, que consiste na zona de possibilidades da criança, ou seja, aquilo que a criança ainda não consegue fazer sozinha, mas consegue fazer com ajuda.

A avaliação formulada a partir do estudo genético aprofundado do desenvolvimento humano, bem como dos processos de aprendizagem, pode contribuir para o desenvolvimento dos processos psicológicos. O uso dos instrumentos por si só não garante a análise qualitativa das dificuldades e das potencialidades. O avaliador deve conhecer a teoria e realizar adequadamente o processo de avaliação, considerar de forma detalhada os resultados e o processo de resolução da tarefa (Quintanar, 2009). Conhecendo o tipo e o nível de ajuda que a criança necessita, um dos objetivos da avaliação, apontado por Quintanar e Solovieva (2003, 2008), é elaborar programas corretivos e de reabilitação que garantem a superação das dificuldades - diferente do que acontece com a avaliação tradicional que rotula a criança e não ajuda a promover seu desenvolvimento.

Este trabalho é produto da pesquisa de mestrado que contemplou um período sanduíche na Maestría en Diagnóstico y Rehabilitación Neuropsicológica, Benemérita Universidad Autónoma de Puebla (BUAP), na cidade de Puebla, no México, fundada em 1994. O programa de pós-graduação é de ordem teórico-prática, contemplando aulas teóricas e intervenções em distintas sedes. Durante esse período foram realizadas participações nas aulas e também nas sedes práticas, foram estudados os instrumentos, o material teórico publicado pelos pesquisadores e também as referências primárias de Vigotski, Luria e Leontiev. A seguir apresentaremos o instrumento desenvolvido nesse programa de mestrado relativo à avaliação da atividade voluntária e experiências vivenciadas nas avaliações de crianças.

\section{A avaliação da atividade voluntária: resultados}

Vale ressaltar que a atividade voluntária é considerada como "o processo da atividade dirigida a um objetivo estabelecido pelo sujeito" (Quintanar \& Solovieva, 2010, p. 46). Para avaliar essa atividade foi criado um protocolo específico denominado Avaliação neuropsicológica da atividade voluntária - Evaluación neuropsicológica de la actividad voluntaria - (Quintanar \& Solovieva, 2010), instrumento dirigido à avaliação dos aspectos voluntários em diferentes atividades e também dentro dos jogos (atividade principal da idade pré-escolar). Nele estão propostos jogos e tarefas que proporcionam uso de diferentes meios de regulação externa, pois a possibilidade de a criança aceitar e utilizar esses meios pode indicar o grau de formação da atividade voluntária.

O instrumento é dividido em cinco seções com indicadores da análise da atividade voluntária: 1. Atividade Lúdica; 2. Atividade voluntária na esfera motora; 3. Atividade voluntária na esfera auditiva; 4. Atenção voluntária no plano gráfico; 5. Recordação involuntária (situacional). 
Referente ao indicador de Atividade Lúdica são propostas duas tarefas. No jogo livre apresentam-se à criança brinquedos e pergunta-se o que se pode jogar com eles. No jogo dirigido propõe-se à criança a tarefa de pegar, a partir de um grupo de cartões colocados no centro, aqueles que pertencem a uma categoria determinada (animais ou frutas) no menor tempo possível e sem cometer erros de categoria. Observa-se o tempo de execução no qual a criança se mantém com o mesmo grau de concentração. Analisa-se o grau de coerência da execução de acordo com o tema do jogo, a estabilidade da atividade, a iniciativa, o interesse da criança e o respeito às regras.

Uma criança avaliada que apresentava dificuldades na atividade voluntária - Iván ${ }^{3}$ de seis anos - propôs uma brincadeira com animais que estavam sobre a mesa, fazendo o som dos animais por um curto período de tempo. A partir da proposta do avaliador de que realizasse uma brincadeira com esses animais, ele conseguiu se concentrar mais tempo, porém não foi capaz de substituir um objeto por outro (por exemplo, lápis por colher para alimentar os animais) e apresentou dificuldades de representar uma ação sem a presença dos objetos, mesmo com ajuda e motivação constante, como o fato de, por exemplo, não haver conseguido assumir um papel de médico proposto em uma brincadeira de papéis. Enquanto outra criança de três anos e um mês Juan - conseguia substituir um objeto por outro durante uma brincadeira (apenas nessa situação) e também seguia um papel no jogo de papéis quando era orientado, porém não propunha nada para o desenvolvimento da história.

A título de ilustrar como uma criança com dificuldade na atividade voluntária resolve a tarefa de jogo dirigido, uma criança avaliada - Adrian de 11 anos $^{4}$ e dois meses - apenas conseguiu formar categorias com orientação e exemplificação, porém essas categorias criadas pela criança não estavam completas (por exemplo, no grupo das aves excluiu a galinha e o pato). Adrian cometeu muitos erros em muitas tarefas porque se antecipava e começava a realizá-las antes que os avaliadores terminassem as instruções, tentando adivinhá-las. Também terminava as tarefas de forma rápida dizendo "já", sem verificação. Portanto, os erros mais comuns cometidos por crianças com dificuldade na atividade voluntária são a falta de compreensão do sentido e significado da informação, respostas adivinhatórias e de confusão global (Solovieva, 2009).

A avaliação da atividade voluntária na esfera motora contém a tarefa de marcha livre, em que se pede à criança que marche livremente. Também contém a tarefa de marcha com palmas, em que se pede à criança que marche ao ritmo das palmas do avaliador. Propõe-se também a marcha com regulação da linguagem, em que a criança deve marchar coordenando seus movimentos com a linguagem do avaliador. Exemplo: "Marche depois de escutar o número três". Por fim propõe-se a tarefa de realização de ações, na qual se pede à criança que realize ações a partir das ordens

3 Os nomes utilizados neste artigo são fictícios.

4 Adrian já tem 11 anos, porém apresentas traços no desenvolvimento característicos da idade pré-escolar. do avaliador. Exemplo: "Caminhe com os braços para cima". Com essas propostas, observa-se a possibilidade da criança se subordinar à marcha e às ações de regulação externa do adulto, ou seja, o grau de desenvolvimento do papel regulador da linguagem e das indicações (palmas).

Nessa tarefa de marchar acompanhando as palmas, Adrian cometeu constantes erros diante do aumento de velocidade ou da mudança de ritmo das palmas. Também apresentou antecipações, quando pedimos para marchar e saltar seguindo instruções orais. Percebemos que Adrian apresentava dificuldades para subordinar-se às regras propostas pelo avaliador. Outra criança avaliada - Iván, de 6 anos - não conseguia realizar essa tarefa, apresentava antecipações, começando a marchar antes da ordem. Quando ele repetia em voz alta a instrução, conseguia realizar a tarefa, mostrando que a linguagem o ajudava a regular seu comportamento. Observamos também que para realizar uma tarefa, Iván precisava de muita motivação, como contato visual constante, para realizar e finalizar a tarefa proposta. Essas duas crianças apresentavam, portanto, dificuldades na atividade voluntária.

Referente ao indicador de atividade voluntária na esfera auditiva tem-se a tarefa de identificação de sons, em que se pede à criança que feche os olhos e identifique os sons. Se a criança apresenta erros, colocam-se objetos sobre a mesa para que identifique a qual objeto se refere o som. Nesse sentido, analisam-se os erros corrigidos e os que não foram corrigidos, bem como a impossibilidade de reconhecer objetos. $\mathrm{Na}$ avaliação da atenção voluntária no plano gráfico, tem-se a Tabela de Schultz, em que se pede à criança que encontre na tabela os números de 1 a 15 em ordem progressiva sem tirar o lápis da folha (vide Figura 1).

\section{Figuras e Tabelas}

\begin{tabular}{|c|c|c|c|c|}
\hline 14 & 18 & 7 & 24 & 21 \\
\hline 22 & 1 & 10 & 9 & 6 \\
\hline 16 & 5 & 8 & 20 & 11 \\
\hline 23 & 2 & 25 & 3 & 15 \\
\hline 19 & 13 & 17 & 12 & 4 \\
\hline
\end{tabular}

Figura 1. Tabela de Schultz (Quintanar \& Solovieva, 2010a). 
Outra tarefa proposta é a de desenhos incompletos, na qual se pede à criança que identifique e marque o que falta no desenho. Propõe-se também a Tabela com figuras (carinhas), em que se pede à criança que marque todas as carinhas iguais à que foi escolhida pelo avaliador. Nessas tarefas observam-se a estratégia e a velocidade da criança para cumprir as tarefas, bem como os erros corrigidos e não corrigidos. Analisam-se a permanência na tarefa e a possibilidade de verificação.

Na tarefa de identificar os detalhes faltantes, Adrian não foi capaz de identificar todos os detalhes faltantes nas figuras. $\mathrm{Na}$ tarefa de Tabela com figuras observamos que seu rastreio era desorganizado e a orientação do avaliador não o ajudava a melhorar sua execução (não seguia a orientação dada).

$\mathrm{Na}$ tarefa de marcar a figura escolhida pelo avaliador, uma criança avaliada - Sebastian, de sete anos e quatro meses - apresentava um rastreio desordenado; no entanto, quando lhe perguntamos qual estratégia ele poderia utilizar para verificar se ele havia marcado todas as figuras, a criança começou a verificar por linhas verticais e verbalizou contando quantas figuras escolhidas tinham em cada fila, conseguindo marcar todas as figuras solicitadas. Na Tabela 1 está a diferença na execução da tarefa pelas duas crianças mencionadas acima.

As possibilidades das crianças de realizar as tarefas propostas de maneira independente sinalizam o nível positivo da consolidação da atividade voluntária ou que se encontra na zona de desenvolvimento atual. A realização de tarefas com a ajuda do adulto, com sua motivação ou constantes repetições mostra que essa atividade se encon- tra na zona de desenvolvimento próximo, enquanto que a impossibilidade total de realizar as tarefas e a presença de erros, apesar da ajuda proporcionada pelo adulto, sinaliza a ausência de atividade voluntária. Dessa forma, essa última situação sinaliza o baixo nível de preparação para a escola e dificuldades na participação em atividade grupais na instituição pré-escolar.

Outra questão que podemos observar no exemplo de resolução de tarefas de Sebastian, que foi mencionado anteriormente, é que essa criança faz o uso da linguagem como estratégia para regular sua conduta. Como exposto antes, a linguagem possui essa função reguladora. De acordo com Luria (1962/2015), a linguagem "formula o objetivo da ação, o correlaciona com o motivo e traça o esquema fundamental daquele problema que o homem levanta" (p. 298). Outro fato que demonstra que essa criança faz o uso da linguagem externa para regular sua conduta foi que sempre repetia a instrução em voz alta antes de realizar a tarefa.

Referente ao quinto descritor presente nesse instrumento - Recordação involuntária intencional - pede-se à criança que feche os olhos e diga os objetos que estão na sala. Observa-se o tempo de execução e se os objetos ditos pela criança têm a ver com as atividades realizadas ou não.

O uso do protocolo é aconselhável para organizar e sistematizar o trabalho do profissional (Quintanar \& Solovieva, 2013) e os instrumentos devem ser utilizados não apenas a partir do método quantitativo, mas principalmente do qualitativo, ou seja, deve-se realizar uma análise qualitativa das dificuldades (Quintanar, 2009). O método qualitativo permite estabelecer em quais condições se impossibilita a execução

Tabela 1. Diferenças nas execuções da tarefa de Tabela com figuras.

\begin{tabular}{|c|c|c|}
\hline Criança & Observações & Execução - Imagem \\
\hline Sebastian & $\begin{array}{l}\text { Rastreio desordenado, porém consegue } \\
\text { marcar todas e verifica já com rastreio } \\
\text { ordenado, contando quantas carinhas } \\
\text { existem em cada fila. }\end{array}$ & 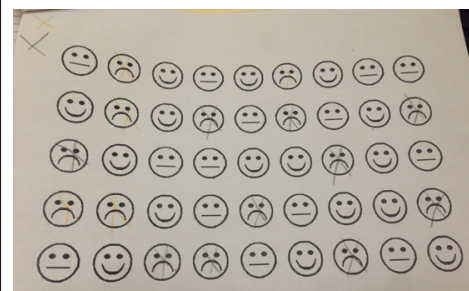 \\
\hline Adrian & $\begin{array}{l}\text { Rastreio organizado ao princípio, mas } \\
\text { quando a tarefa se complexifica seu } \\
\text { rastreio é desordenado e a orientação do } \\
\text { avaliador não o ajuda. }\end{array}$ & 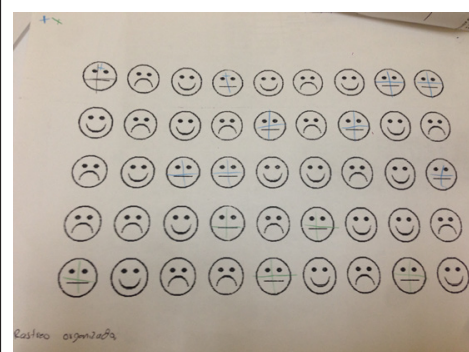 \\
\hline
\end{tabular}

Nota. Tabela construída por nós. 
de determinada ação e em quais são possíveis a compensação das dificuldades. Para se avaliar a atividade voluntária, observa-se, portanto, na execução das tarefas, se a criança necessita do uso de regulação externa, a possibilidade de aceitar ou não o uso desses meios e se apresenta perda de objetivo nas atividades.

Para precisar se os erros sinalizam o baixo nível da aquisição da atividade voluntária, relacionado com a pobre situação social de desenvolvimento da criança, com a inadequada metodologia da educação pré-escolar e se adicionalmente existem algumas causas neuropsicológicas relacionadas ao funcionamento cerebral específico, devem-se utilizar as provas propriamente neuropsicológicas, as quais permitirão analisar os aspectos clínicos (Quintanar \& Solovieva, 2003, 2010; Quintanar \& Solovieva, 2013).

\section{Discussão}

O psicólogo é frequentemente solicitado a avaliar crianças com problemas no comportamento voluntário expresso na falta de controle do comportamento, como a falta de atenção. Assim, a psicologia histórico-cultural nos instrumentaliza a compreender melhor o fenômeno e desenvolver formas de avaliação que condizem com a teoria.

As avaliações apresentadas aqui foram solicitadas pelos pais, que tinham como expectativas levar para a escola e para suas casas estratégias para ajudar as crianças a aprenderem e se desenvolverem. Em uma "avaliação tradicional", provavelmente algumas dessas crianças avaliadas e exemplificadas aqui poderiam receber um diagnóstico que poderia rotulá-las, imobilizando os trabalhos de educadores e cuidadores.

O desenvolvimento de instrumentos se faz interessante porque organiza e sistematiza o trabalho do neuropsicólogo e/ou do psicólogo. No entanto, assim como os instrumentos são fundamentados pela teoria em questão, também o avaliador deve ser grande conhecedor da teoria para conseguir avaliar de uma forma não apenas quantitativa, mas também qualitativa. Uma das carências mais importante das avaliações utilizadas, construídas sob outros enfoques, é a impossibilidade de caracterizar adequadamente a dinâmica da idade pré-escolar e conhecer as neoformações psicológicas centrais. Já o protocolo apresentado neste trabalho permite cumprir com os objetivos fundamentais da avaliação psicológica infantil, que são: 1. Investigar como transcorre o período da idade pré-escolar em geral; 2. Realizar a análise da estrutura da idade: determinar as neoformações centrais, sendo a atividade voluntária uma delas; 3 . Identificar os aspectos fortes e débeis nos níveis psicológicos e neuropsicológicos; 4. Estabelecer o nível no qual as ações voluntárias são mais acessíveis: verbal ou não verbal; 5 . Contribuir para o trabalho pedagógico e psicológico a partir do uso de atividades correspondentes.

Vale destacar que o trabalho realizado pela instituição visitada corresponde a uma avaliação de ordem neuropsicológica clínica. A avaliação realizada a partir do embasamento teórico presente tanto no instrumento quanto no conhecimento avaliador possibilita, diferentemente das avaliações tradicionais, a promoção do desenvolvimento, configurando como importante trabalho para a criança, os pais e a escola. Dessa forma podemos pensar que essa área tem a contribuir para as pesquisas e atuações do psicólogo escolar e educacional, bem como este campo pode contribuir para aquele com os estudos sobre o entendimento da produção da queixa escolar. Entendemos que o encontro dessas duas áreas de conhecimento referentes ao desenvolvimento humano pode ser muito rico e importante para o avanço dos estudos nessa temática.

Esperamos que este trabalho possa contribuir para o fortalecimento da teoria no Brasil, auxiliando futuras pesquisas sobre o tema. Também esperamos contribuir para a instrumentalização de psicólogos e outros profissionais relacionados à educação, para que esses enfrentem os crescentes diagnósticos estigmatizantes, que apenas apresentam um determinado rótulo, mas não conduzem a um trabalho geral com a criança.

\section{Referências}

Asbahr, F. S. F.; Lopes, J. S. (2006). A culpa é sua. Psicologia USP, $17(1), 53-73$

Elkonin, D. B. (1987). Sobre el problema de la periodización del desarrollo psíquico en la infancia. In: Davidov, D.; Shuare, Y. (Orgs.), La psicología evolutiva y pedagógica en la URSS: Antología. Moscou: Ed. Progreso.

Facci, M. G. D.; Eidt, N. M.; Tuleski, S. C. (2006). Contribuições da teoria histórico-cultural para o processo de avaliação psicoeducacional. Psicologia USP, 17(1), 99-124.

Facci, M. G. D., Tessaro, N. S.; Leal, Z. F. R. G.; Silva, V. G.; Roma, C. G. (2007). Psicologia Histórico-Cultural e Avaliação Psicológica: o processo ensino aprendizagem em questão. Psicologia Escolar e Educacional, 11 (2), 323-338.

Lázaro García, E. (2009). Identificación temprana de dificultades para la actividad escolar. In: Quintanar, L.; Solovieva, Y.; Lázaro García, E.; Bonilla Sánchez, M. R.; Mejía, L.; Eslava Cobos, J.; Flores Ramos, E. (Orgs.), Dificultades en el proceso lectoescritor (pp. 23-34). México: Trillas.

Leontiev, A. N. (1972). Atividade e Consciência (Souza e Silva, M.J., Trad.). Licença Creative Commons. Recuperado: 08 dez. 2016. Disponível: https://www.marxists.org/portugues/leontiev/1972/ mes/atividade.htm.

Leontiev, A. N. (1984). Actividad, conciencia y personalidad. México: Editorial

Leontiev, A. N. (1991). Os princípios do desenvolvimento mental e o problema do atraso mental. In: Luria, A. R.; Leontiev, A. N.; 
Vygotsky, L. S. (Orgs.), Psicologia e Pedagogia: bases psicológicas da aprendizagem e do desenvolvimento (pp. 87-106). São Paulo: Moraes. (Trabalho original publicado em 1959).

Leontiev, A. N. (2009). La importancia del concepto de la actividad objetal para la psicología. In: Quintanar, L.; Solovieva, Y. (Orgs.), Las funciones psicológicas en el desarrollo del niño (pp. 54-63). México: Trillas. (Trabalho original publicado em 1972).

Leontiev, A. N. (2010). El desarrollo psicológico en la edad preescolar. In: Solovieva, Y.; Quintanar, L. (Orgs.), Antología del desarrollo psicológico del niño en edad preescolar (pp.17-26). México: Trillas.

Luria, A. R. (1991). Curso geral de psicologia I. Rio de Janeiro: Editora Civilização Brasileira.

Luria, A. R. (2015). Las funciones corticales del hombre ( $3^{\mathrm{a}}$ ed.). México: Fontamara. (Trabalho original publicado em inglês em 1962).

Marx, K. (2013). O processo de trabalho e o processo de valorização. In: Marx, K., O Capital - livro I (1 ${ }^{\text {a }}$ ed., pp. 255-276). São Paulo: Boitempo. (Trabalho original publicado em 1867).

Mello, S. A. (2013). Prefácio. In: Quintanar, L.; Solovieva, Y. (Orgs.), Avaliação das neoformações psicológicas da idade pré-escolar (pp. 7-11). Uberlândia, MG: Edufu.

Patto, M. H. S. (1990). A produção do fracasso escolar: histórias de submissão e rebeldia. São Paulo: T.A. Queiroz.

Quintanar, L. (2009). Formas de evaluación de las causas de las dificultades en la lectoescritura. In: Quintanar, L.; Solovieva, Y.; Lázaro García, E.; Bonilla Sánchez, M. R.; Mejía, L.; Eslava Cobos, J.; Flores Ramos, E. (Orgs.), Dificultades en el proceso lectoescritor (pp. 35-50). México: Trillas.

Quintanar, L.; Solovieva, Y. (2003). Manual de Evaluación Neuropsicológica Infantil. México: Benemérita Universidad Autónoma de Puebla.

Quintanar, L.; Solovieva, J. (2008). Aproximación histórico-cultural: Fundamentos teórico metodológicos. In: Eslava, J.; Mejia, L.; Quintanar, L.; Solovieva, Y. (Orgs.), Los trastornos del aprendizaje: perspectivias neuropsicológicas (pp. 145-181). Colombia: Magisterio.

Quintanar, L.; Solovieva, Y. (2010). Evaluación Neuropsicológica de la Actividad del Niño preescolar. Puebla, Mx: Benemérita Universidad Autónoma de Puebla.

Quintanar, L.; Solovieva, Y. (2013). Avaliação das neoformações psicológicas da idade pré-escolar. Uberlândia, MG: Edufu

Salmina, N. G.; Filimonova, O. G. (2001). Diagnóstico y corrección de la actividad voluntaria en la edad preescolar y escolar. Tlaxcala, Mx: Universidad Autónoma de Tlaxcala
Smirnova, E. O. (2010). El desarrollo de la voluntad y de la voluntariedad en la ontogenia temprana. In: Solovieva, Y.; Quintanar, L. (Orgs.), Antología del desarrollo psicológico del niño en edad preescolar (pp. 46-58). México: Trillas.

Sokolov, A. N.; Rubinshtein, S. L. (1969). Objeto, problemas y métodos de la Psicologia. In: Smirnov, A. A.; Leontiev, A. N.; Rubinstein, S. L.; Tieplov, B. M. (Orgs.), Psicologia. México: Editorial Grijalbo.

Solovieva, Y. (2009). Método de formación de lectura en niños con dificultades. In: Quintanar, L.; Solovieva, Y.; Lázaro García, E.; Bonilla Sánchez, M. R.; Mejía, L.; Eslava Cobos, J.; Flores Ramos, E. (Orgs.), Dificultades en el proceso lectorescritor (pp. 77-96). México: Trillas

Solovieva, Y. (2014). La actividad intelectual en el paradigma históricocultural. México: Ediciones CEIDE

Solovieva, Y.; Lázaro, E.; Quintanar, L. (2006). Diagnóstico psicológico en la edad preescolar. Neuropediatría, 4 (1), 35-50.

Solovieva, Y.; Quintanar, L. (2001). Prologo a la edicion en español. In: Salmina, N. G.; Filimonova, O. G., Diagnóstico y corrección de la actividad voluntaria en la edad preescolar y escolar (pp. 5-8). Universidad Autónoma de Tlaxcala. Tlaxcala, México.

Solovieva, Y.; Quintanar, L. (2014). Principios y objetivos para la correccion y el desarrollo en la neuropsicologia infantil. In: Patiño, H.; López, A. (Orgs.), Prevención y evaluación en psicología. Aspectos teóricos y metodológicos (pp. 61-74). México: Manual Moderno.

Vieira, A. P. A. (2016). Contribuições da Psicologia Histórico-Cultural para o estudo do desenvolvimento do autocontrole/autorregulação: Um estudo introdutório. Monografia. Universidade Estadual de Maringá, Maringá, PR.

Vigotski, L. S. (2009). A construção do pensamento e da linguagem ( $2^{\mathrm{a}}$ ed.). São Paulo: Martins Fontes (Trabalho original publicado em 1934).

Vigotsky, L. S. (1996). Obras escogidas Tomo IV. Madrid: Ed. Visor.

Vygotsky, L. S. (2012). Obras escogidas Tomo III. Madrid: Machado Grupo de Distribución. (Grande parte dos textos foi escrita em 1931).

Xomskaya, E. (2002). La escuela neupsicológica de A. R. Luria (Solovieva, Y \& Quintanar, L., trad.). Revista Española de Neuropsicología, 4 (2-3), 130-150.

Recebido em: 02 de fevereiro de 2017 Aceito em: 13 de julho de 2017 
License information: This is an open-access article distributed under the terms of the License (type CC-BY), which permits unrestricted use, distribution and reproduction in any medium, provided the original article is properly cited. 